\title{
Optimal design of a large-span spatial structure based on dynamic elastic-plastic analysis
}

\author{
Feipeng Liu ${ }^{1}$, Xuejun Liu ${ }^{2}$, Lvhe Dong ${ }^{3}$, Hui Tian ${ }^{4}$, Dong Li ${ }^{5}, \mathrm{Xu} \mathrm{Huang}^{6}$ \\ 1,2, ${ }^{3}$ Northwest Electric Power Design Institute Co., Ltd., Xi'an, 710075, China \\ $4,5,6$ Key Laboratory of New Technology for Construction of cities in Mountain Area, Chongqing \\ University, Ministry of Education, Chongqing, 400045, China \\ ${ }^{4,5,6}$ School of Civil Engineering, Chongqing University, Chongqing, 400045, China \\ ${ }^{4}$ Corresponding author \\ E-mail: 1liufeipeng@nwepdi.com, ${ }^{2}$ liuxuejun@nwepdi.com, ${ }^{3}$ donglvhe@nwepdi.com,

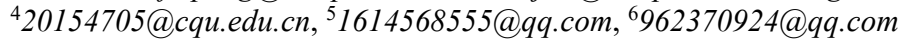

Received 15 September 2020; received in revised form 3 October 2020; accepted 13 October 2020 DOI https://doi.org/10.21595/vp.2020.21693

Check for updates

Copyright (C) 2020 Feipeng Liu, et al. This is an open access article distributed under the Creative Commons Attribution License, which permits unrestricted use, distribution, and reproduction in any medium, provided the original work is properly cited.

\begin{abstract}
With the expansion of the urban areas and the rapid growth of the urban population, the disposal of large amounts of domestic waste has become a problem faced by large cities. To solve this problem, many MSW incineration power plants have been continuously built. As a typical large-span spatial structure of waste incineration power plant, how to achieve economic, beautiful, and environmentally friendly design goals under the premise of meeting the requirements of the production process is an important problem currently facing. In this paper, a structural design optimization method based on damage index is proposed. Taking a large-span mixed structure of a MSW incineration power plant as an example, the paper firstly uses the dynamic elastic-plastic time history analysis method to evaluate its seismic performance, and then optimizes the structure according to the damage degree of the structure under small and large earthquakes design. The results show that under the premise of meeting the requirements of the code, this method can ensure that the degree of structural damage under the earthquake remains almost unchanged, while significantly reducing the amount of building materials and reducing the cost. At the same time, this method is more direct, simple, and effective than optimization design methods based on experience and internal forces of structural members.
\end{abstract}

Keywords: MSW incineration power plants, large-span structure, dynamic response, performance, optimization design.

\section{Introduction}

With the development of large-scale, complicated, and diversified civil engineering structures, structural optimization design becomes more and more important, especially for large-span spatial structures with complex shapes. All over the world, large-scale public buildings at home and abroad are premised on large-span spatial structures, ranging from sports buildings directly related to the people's physical and mental health, to exhibition buildings that promote information exchanges, to large-scale transportation buildings, entertainment facilities, These large-scale public buildings, such as theaters and music academies, require a large-span structural system to support them [1]. Based on the dynamic elastic-plastic time analysis of a large-span structure under the fortification intensity of 8 degrees, the structure is optimized and the seismic performance and economic efficiency of the structure before and after optimization are systematically compared.

\section{MSW incineration power plant model}

\subsection{Project profile}

The structure has a length of 132.89 meters and a width of 44 meters, which is a large-span 
spatial structure Fig. 1(a). The building adopts a steel structure-reinforced concrete-shear wall hybrid structure. This project is based on the 8-degree seismic fortification intensity to conduct dynamic elastic-plastic time history analysis Fig. 1(b).

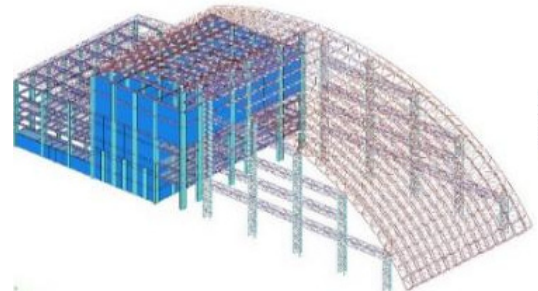

a)

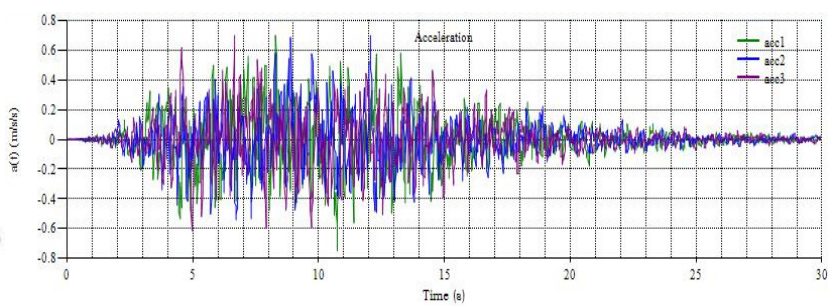

b)

Fig. 1. a) A three-dimensional view of the model, b) time history diagram of seismic wave acceleration

\subsection{Analytical model}

The dynamic elastic-plastic analysis method based on explicit integration will be used in this project. This method doesn't make any theoretical simplification, and directly simulates the nonlinear response of the structure under the action of seismic force. It has the following advantages:

1) Complete dynamic time history characteristics: It can better reflect the internal force distribution of components under different phase differences, especially for floor slabs [2].

2) Geometric nonlinearity: The dynamic balance equation of the structure is established on the geometric state of the structure after deformation, and the "P- $\Delta$ " effect and nonlinear buckling effect are all accurately considered [2].

3) Material nonlinearity: simulate directly on the stress-strain constitutive relationship.

4) It can accurately simulate the damage of the structure to the collapsed form.

The nonlinear material model of steel adopts the bilinear kinematic hardening model. During the cycle, there is no stiffness degradation and the Bauschinger effect is considered. The yield ratio of steel is set to 1.2 , and the ultimate plastic strain corresponding to the ultimate stress is 0.025. The one-dimensional concrete material model adopts the uniaxial constitutive model specified by the specification. The characteristics of concrete hysteresis, stiffness degradation and strength degradation, and its axial compression and axial tensile strength standard values are adopted in accordance with Ref. [3]. Shear walls and floors adopt elastoplastic layered shell elements. The fiber model is used to simulate beam, column, inclined bracing and truss.

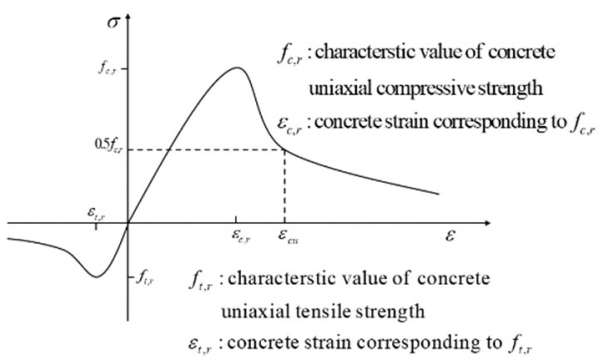

a)

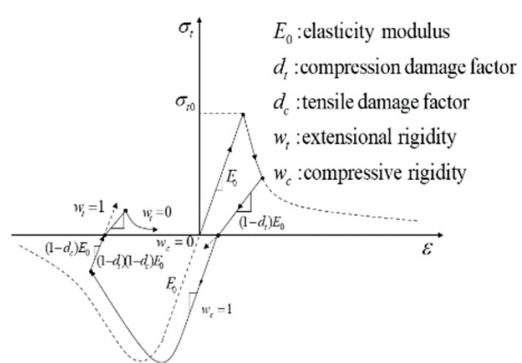

b)

Fig. 2. a) Concrete uniaxial stress-strain curve, b) concrete stiffness recovery diagram

\section{Performance-based optimization design}

\subsection{Structural performance level before optimization design}

Concrete members should not only consider the plastic strain of the steel bar, but also pay 
attention to the compression damage of the concrete material, which is expressed by the damage factor. Based on the seismic wave in Fig. 1 for dynamic elastic-plastic time history analysis, the drift ratio is much smaller than the code limit 1/50 [4], and the damage to the structure or member is also very small.

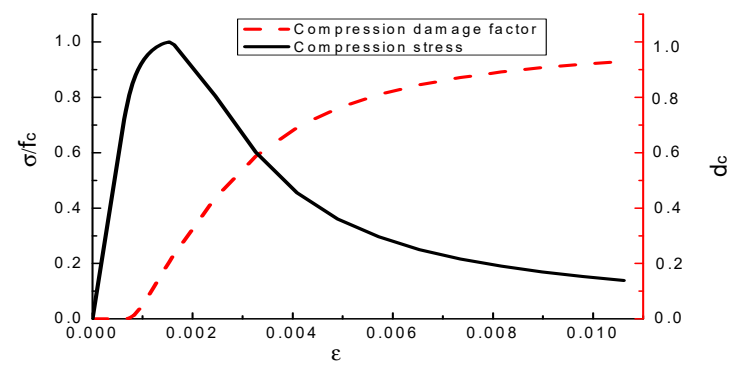

Fig. 3. Correspondence diagram of concrete bearing capacity and compressive damage factor

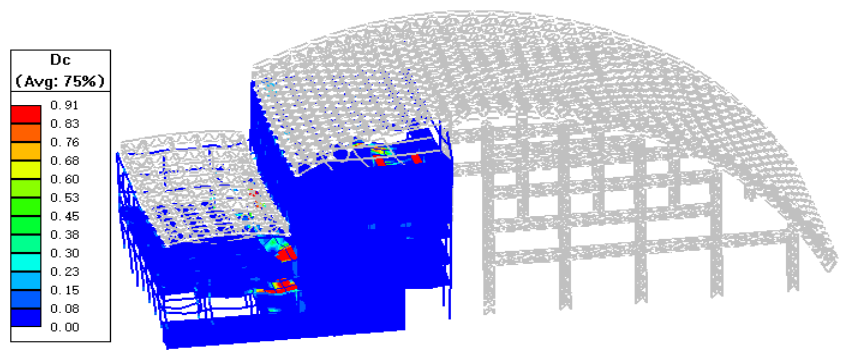

Fig. 4. Concrete compression damage
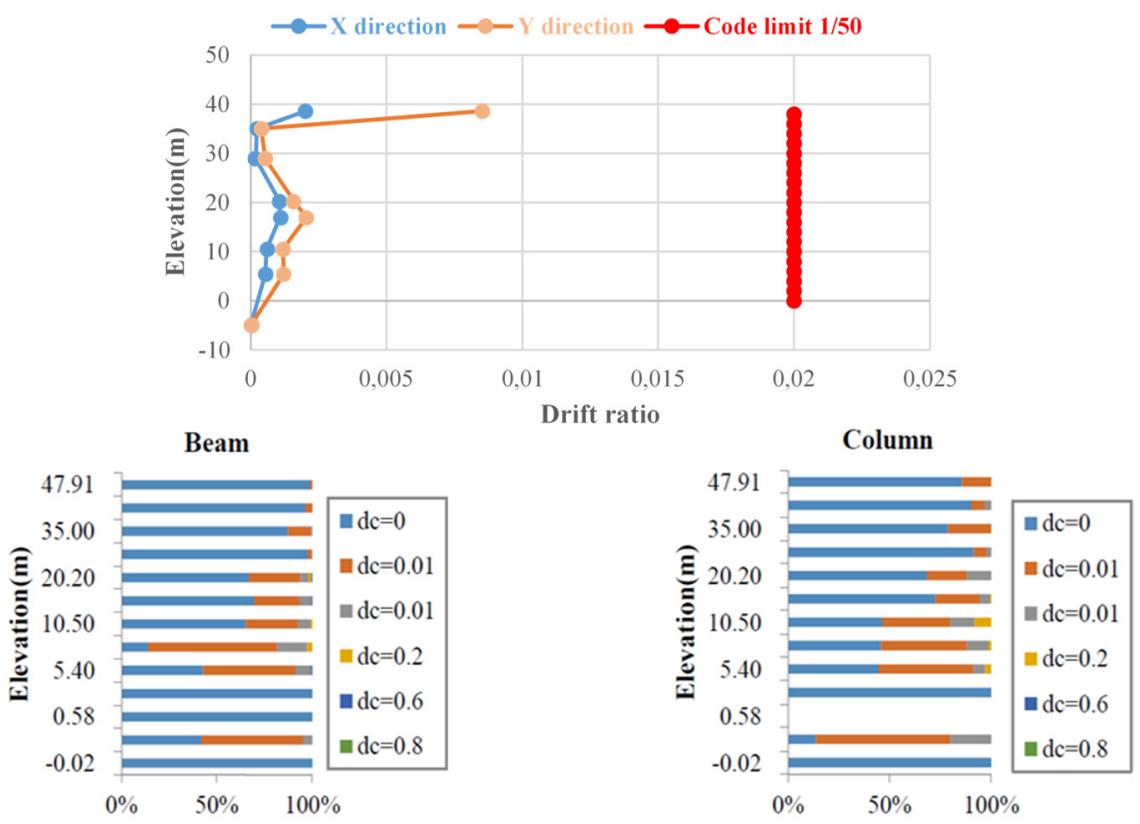

Fig. 5. Deformation and beam-column damage statistics (When $\mathrm{dc}=0.01$, $\mathrm{dt}$ is not equal at this time)

\subsection{Optimize design and performance level}

The optimization design is mainly carried out according to the performance of the structure, and its content mainly includes the optimization of the member section size and the change of the 
constraint form. At the junction of concrete and steel grids, using GAP units to simulate sliding bearings can effectively solve the problems of deformation coordination and stress concentration.

Table 1. Optimization of beam and column section size

\begin{tabular}{|c|c|c|c|c|c|}
\hline \multirow{2}{*}{ ID } & \multicolumn{2}{|c|}{ Member } & \multirow{2}{*}{ Before } & \multirow{2}{*}{ After } & \multirow{2}{*}{ Number } \\
\hline & Material & Type & & & \\
\hline 9 & $\mathrm{C} 40$ & RC Beam & $400 \times 700$ & $500 \times 700$ & 62 \\
\hline 7 & $\mathrm{C} 40$ & RC Beam & $300 \times 500$ & $300 \times 450$ & 60 \\
\hline 4 & $\mathrm{C} 40$ & RC Beam & $300 \times 600$ & $300 \times 550$ & 94 \\
\hline 14 & $\mathrm{C} 45$ & RC Beam & $400 \times 600$ & $450 \times 500$ & 84 \\
\hline 10 & $\mathrm{C} 45$ & RC Column & $1200 \times 700$ & $1000 \times 800$ & 88 \\
\hline 12 & $\mathrm{C} 45$ & RC Column & $1400 \times 700$ & $1400 \times 800$ & 134 \\
\hline 8 & $\mathrm{C} 45$ & RC Column & $700 \times 700$ & $600 \times 600$ & 68 \\
\hline 29 & $\mathrm{C} 45$ & RC Column & $700 \times 1500$ & $800 \times 1000$ & 57 \\
\hline 13 & Q235 & Steel & $\mathrm{D} 159 \times 6$ & $\mathrm{D} 152 \times 6$ & 367 \\
\hline 48 & Q235 & Steel & DS140 $\times 8$ & DS133×6 & 576 \\
\hline 49 & Q345 & Steel & $\mathrm{H} 1400 \times 500 \times 25 \times 40$ & $\mathrm{H} 1500 \times 500 \times 25 \times 40$ & 42 \\
\hline 50 & Q235 & Steel & DS219×12 & DS $180 \times 8$ & 480 \\
\hline 35 & Q235 & Steel & DS273 $\times 14$ & DS299 $\times 16$ & 184 \\
\hline
\end{tabular}

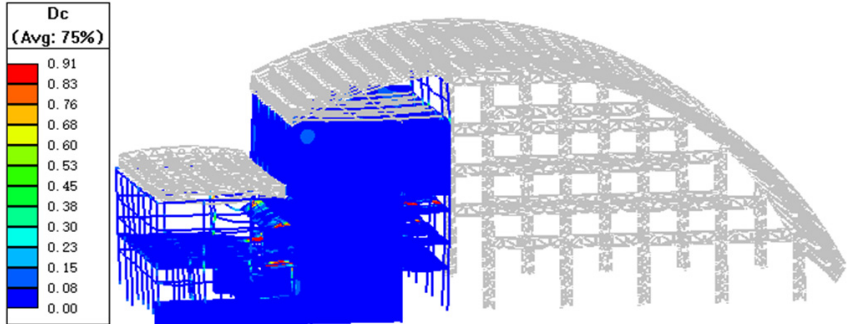

Fig. 6. Concrete compression damage
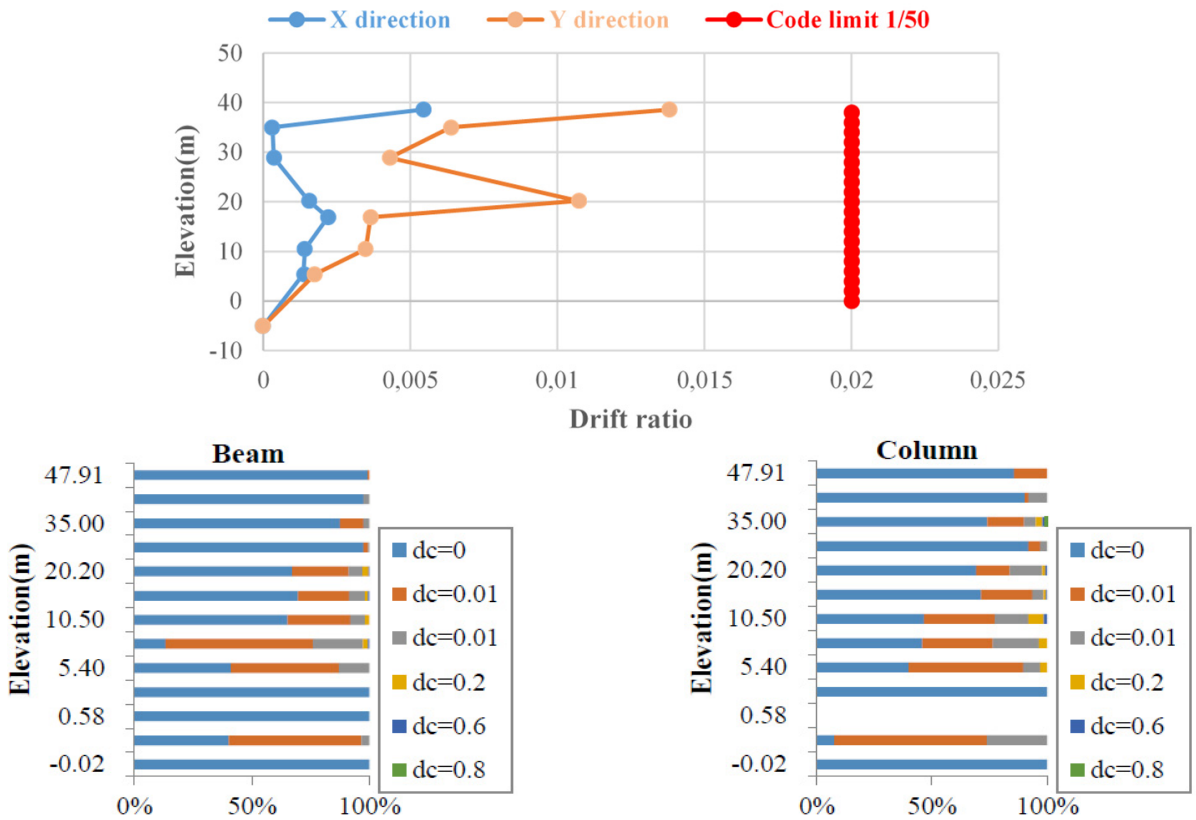

Fig. 7. Deformation and beam-column damage statistics (After optimizing the design) 
OPTIMAL DESIGN OF A LARGE-SPAN SPATIAL STRUCTURE BASED ON DYNAMIC ELASTIC-PLASTIC ANALYSIS. Feipeng Liu, XueJun Liu, LvHe Dong, Hui Tian, Dong Li, Xu HuAng

Table 2. Material utilization amount (Unit: Tons)

\begin{tabular}{|c|c|c|c|c|}
\hline \multirow{2}{*}{ Material } & \multicolumn{4}{|c|}{ Project } \\
\cline { 2 - 5 } & Before & After & The amount saved & Ratio (\%) \\
\hline Concrete & 11639.68 & 10915.80 & 723.8590 & 6.22 \\
\hline Rebar & 248.5598 & 230.7050 & 17.8544 & 7.18 \\
\hline Steel & 852.3685 & 750.2900 & 102.0790 & 11.98 \\
\hline
\end{tabular}

\section{Conclusions}

In this paper, a dynamic elastic-plastic time history analysis of a large-span structure based on the seismic fortification intensity of 8 degrees is carried out, and the optimal design is directly carried out based on the damage of the structure or members, and finally some design suggestions are given. The optimized design results of the model show that the amount of concrete saved and the amount of steel saved are $6.3 \%$ and $11.9 \%$ of the original structure, respectively. In general, the optimized model is an ideal solution in terms of economy and seismic performance.

\section{References}

[1] Li Qinghai, Zhang Yanguo, Chen Yong, Meng Aihong, Pang Jinfu, Chen Changhe Combination utilization of air preheater with low-pressure economizer in MSW incineration power plants. Power Engineering, Vol. 6, 2006, p. 854-858, (in Chinese).

[2] Technical Specification for Concrete Structures of Tall Building. China Architecture Publishing, (in Chinese).

[3] GB 50010-2010 Code for Design of Concrete Structures. Beijing China Architecture and Buildings Press, 2011, (in Chinese).

[4] GB 50011-2010 Code for Seismic Design of Buildings. Beijing China Architecture and Buildings Press, 2010, (in Chinese).

[5] Guo Lijun Application Research on Large-Span Spatial Structure Optimization Design. Hunan University, 2016, (in Chinese). 